\title{
Effect of Milling Tools on the Microstructure and Property of Cu-Based Composites Prepared by Mechanical Alloying
}

\author{
Ruo-Shan Lei ${ }^{1} \cdot$ Ming-Pu Wang ${ }^{2}$
}

Received: 28 October 2016/Revised: 31 December 2016/Published online: 2 May 2017

(C) The Chinese Society for Metals and Springer-Verlag Berlin Heidelberg 2017

\begin{abstract}
Cu}$ and $\mathrm{Nb}$ powders were used as starting materials to produce $\mathrm{Cu}-\mathrm{Nb}$ and $\mathrm{Cu}-\mathrm{NbC}-\mathrm{WC}$ composites by mechanical alloying. X-ray diffraction, scanning electron microscopy, transmission electron microscopy observations and microhardness measurements have been used to study the effects of milling tools on the phase, microstructure and property of the composites. The results revealed that a single-phase nanocrystalline solid solution was obtained using stainless steel vials and balls (Alloy 1). Nevertheless, $\mathrm{Cu}-7 \mathrm{wt} \% \mathrm{Nb}$ powders milled by tungsten carbon vials and balls exhibited an amorphous phase (Alloy 2). The as-milled powders were then vacuum hot-pressing sintered. The microstructure of sintered Alloy 1 consisted of $\mathrm{Nb}$ nanoparticles and $\mathrm{Cu}$ nanograins. Instead, Alloy 2 showed a microstructure with $\mathrm{NbC}$ nanoparticles and WC submicron-sized particles dispersed throughout the $\mathrm{Cu}$ matrix. Furthermore, Alloy $2(\sim 322 \mathrm{HV})$ had a higher microhardness than Alloy 1 ( 302 HV).
\end{abstract}

KEY WORDS: Mechanical alloying; Cu-based composite; Mechanical property; Nanostructured materials

\section{Introduction}

Mechanical alloying (MA) is one of the most useful techniques used to produce supersaturated solid solutions, nanocrystalline alloys and amorphous systems, etc [1-6]. Moreover, MA process combined with subsequent consolidation process can fabricate bulk materials with wellcontrolled microstructures, morphologies and properties. For example, Bachmaier et al. [4] reported that the MA-ed nanocrystalline $\mathrm{Al}-3.2$ at.\% $\mathrm{Mn}$ alloy showed a very high hardness value of $4 \mathrm{GPa}$. During MA process, the collision

Available online at http://link.springer.com/journal/40195

Ruo-Shan Lei

leiruo@163.com; leiruo@gmail.com

1 College of Materials Science and Engineering, China Jiliang University, Hangzhou 310018, China

2 School of Materials Science and Engineering, Central South University, Changsha 410083, China between milling tools (such as balls and containers) and powders takes place, which causes the severe mechanical deformation of the powders accompanied by cold-welding and fracturing [1-6]. Generally, a higher density of milling tools will transfer more impact energy to the powders. Hence, they are important to control the milling intensity, which remarkably affects the phase and microstructural evolution in MA-ed powders as well as the properties of the compacted products. Currently, the most common types of materials used for milling tools are hardened steel, stainless steel, tungsten carbon (WC) and tool steel, etc [1].

In recent years, the increasing interest in $\mathrm{Cu}-\mathrm{Nb}$ and $\mathrm{Cu}-\mathrm{NbC}$ composites is due to their high mechanical strength and relatively good electrical conductivity [7-16]. It was reported that the MA-ed nanocrystalline $\mathrm{Cu}-5$ at.\% $\mathrm{Nb}$ alloy showed a hardness of $300 \mathrm{HV}$ and a conductivity of 50\% IACS [7]. Long et al. [16] also reported that MA-ed $\mathrm{Cu}-15$ vol.\% NbC composite obtained an extremely high microhardness of $377 \mathrm{HV}$. However, most investigations to date have focused on $\mathrm{MA}$ of $\mathrm{Cu}-\mathrm{Nb}$ and $\mathrm{Cu}-\mathrm{NbC}$ composites using stainless steel balls and vials. There is a little 
information to be reported regarding the effect of milling tools on the microstructure and property of $\mathrm{Cu}-\mathrm{Nb}$ and $\mathrm{Cu}-$ $\mathrm{NbC}$ composites synthesized by MA and subsequent consolidation process.

In the present work, a mixture of $\mathrm{Cu}$ and $\mathrm{Nb}$ powders with a composition corresponding to $7 \mathrm{wt} \% \mathrm{Nb}$ was subjected to MA and subsequent hot pressing. WC and stainless steel were the two types of materials used to make the grinding vessels and balls. The effects of milling tools on the phase transformation, microstructural evolution and mechanical property of the as-milled powders and sintered products were investigated. The relationship between the microstructure and mechanical property was also discussed.

\section{Experimental}

Original $\mathrm{Cu}$ (99.6 wt\% pure) and $\mathrm{Nb}$ (99.4 wt $\%$ pure) powders with a composition of $\mathrm{Cu}-7 \mathrm{wt} \% \mathrm{Nb}$ were MA-ed in a QM-1SP4 planetary ball mill under argon atmosphere. Two different methods were used to prepare the powders. In the first method (Alloy 1), the milling vials and balls were made of stainless steel (density of $7.9 \mathrm{~g} / \mathrm{cm}^{3}$ ). Three hundred $0.3 \mathrm{~cm}$ (diameter), eighty-five $0.5 \mathrm{~cm}$ and four $1 \mathrm{~cm}$ stainless steel balls were used. The weight ratio of ball to powder was kept to be 15:1. The MA process was carried out with a rotation speed of $300 \mathrm{rpm}$ for $40 \mathrm{~h}$ at room temperature. To avoid an increase in temperature, the process was stopped for $15 \mathrm{~min}$ after each $15 \mathrm{~min}$ of milling. In the second method (Alloy 2), the material used for the milling jars and balls was WC (density of $14.5 \mathrm{~g} / \mathrm{cm}^{3}$ ), and the diameters of the used balls were $0.3,0.5$ and $0.8 \mathrm{~cm}$, respectively. Other milling conditions were the same with those used in the first method.

After milling for $40 \mathrm{~h}$, both of Alloy 1 and Alloy 2 powders were taken for annealing at $560{ }^{\circ} \mathrm{C}$ for $1 \mathrm{~h}$ under a hydrogen atmosphere. Then the annealed powder was compacted by vacuum hot-pressing sintering with a load of $30 \mathrm{MPa}$ for $2 \mathrm{~h}$ at $900{ }^{\circ} \mathrm{C}$.

The components of the alloys were analyzed by X-ray diffraction (XRD) using a standard diffractometer (DMAX2000) with $\mathrm{Cu} K_{\alpha}$ radiation and a graphite monochromator. Williamson-Hall method was used to evaluate the average grain size and lattice strain of the samples after fitting the XRD patterns via the Pearson-VII function [12]. Scanning electron microscopy (SEM, Sirion 200) with energy dispersive spectrometer (EDS), transmission electron microscopy (TEM) and high-resolution TEM (HRTEM) observations on an FEI TecnaiG2 and a JEOL JEM-2100 operating at $200 \mathrm{kV}$, respectively, were used to characterize the morphology and structure. Samples for TEM investigation were prepared by mechanical grinding, conventional dimpling and finally ion-thinning. A minimum of 10 Vickers hardness measurements were performed on each consolidated samples using an HVA-10A Vickers hardness machine with a $3 \mathrm{kgf}$ load for $15 \mathrm{~s}$.

\section{Results and Discussion}

\subsection{Phase Evolution and Microstructure Observation of MA-ed Powders}

Figure 1a shows the XRD patterns of milled powders of Alloy 1. As shown, the effect of milling time on the $\mathrm{Cu}$ diffraction peaks is threefold: peak broadening, intensity loss and peak shifting. And $(110)_{\mathrm{Nb}}$ peak totally disappears after milling for $20 \mathrm{~h}$, suggesting the dissolution of $\mathrm{Nb}$ into the $\mathrm{Cu}$ matrix. The result is in good agreement with the previous investigations, which have reported that MA of $\mathrm{Cu}-\mathrm{Nb}$ powders can result in the formation of supersaturated solid solutions, though a negligible mutual solid solubility is shown in $\mathrm{Cu}-\mathrm{Nb}$ phase diagram [7-13]. Botcharova et al. [11] and Benghalem and Morris [8] have reported that the dislocation pumping mechanism and the formation of nanocrystalline structure are responsible for the extended solid solution of $\mathrm{Nb}$ in $\mathrm{Cu}$. Besides, our group has recently found that the allotropic transformation of $\mathrm{Nb}$ and the generation of disclination defects also benefit the diffusion of $\mathrm{Nb}$ into the $\mathrm{Cu}$ matrix during MA [13]. On the other hand, it has been proposed that the increased elastic strain and surface energy induced by milling can enhance the solid solubility limit on the basis of thermodynamic analysis [10].

The XRD patterns of milled powders of Alloy 2 as shown in Fig. $1 \mathrm{~b}$ reveal that $(110)_{\mathrm{Nb}}$ peak is undetectable after $10 \mathrm{~h}$ milling. In addition, the $\mathrm{Cu}$ peaks show a remarkable peak broadening and intensity reduction after milling. After $30 \mathrm{~h}$ milling, $\mathrm{Cu}$ peaks are replaced by the diffuse intensity distribution from the amorphous $\mathrm{Cu}$ phase (the inset of Fig. 1b), which keeps stable with further milling to $40 \mathrm{~h}$. Since the Gibbs free energy of the $\mathrm{Cu}-\mathrm{Nb}$ solid solution is smaller than that of the amorphous phase within the composition range of 0-28 wt $\% \mathrm{Nb}$ at room temperature, milling of dilute $\mathrm{Cu}-\mathrm{Nb}$ powders leads to the formation of solid solution in Ref. [18]. To the author's knowledge, this is the first time that the amorphous $\mathrm{Cu}-\mathrm{Nb}$ phase instead of supersaturated crystalline solid solutions has been produced in the dilute $\mathrm{Cu}-\mathrm{Nb}$ system by MA at room temperature. References [1] and [19] have suggested that increased milling energy can introduce more lattice defects and enhance the stored energy in the powders, which benefits the destabilization of the crystalline phase. In the present study, since the density of WC is much larger than that of stainless steel, higher impact force and collision energy will be transferred to the powders by using WC balls, leading to the loss of crystalline order and the 

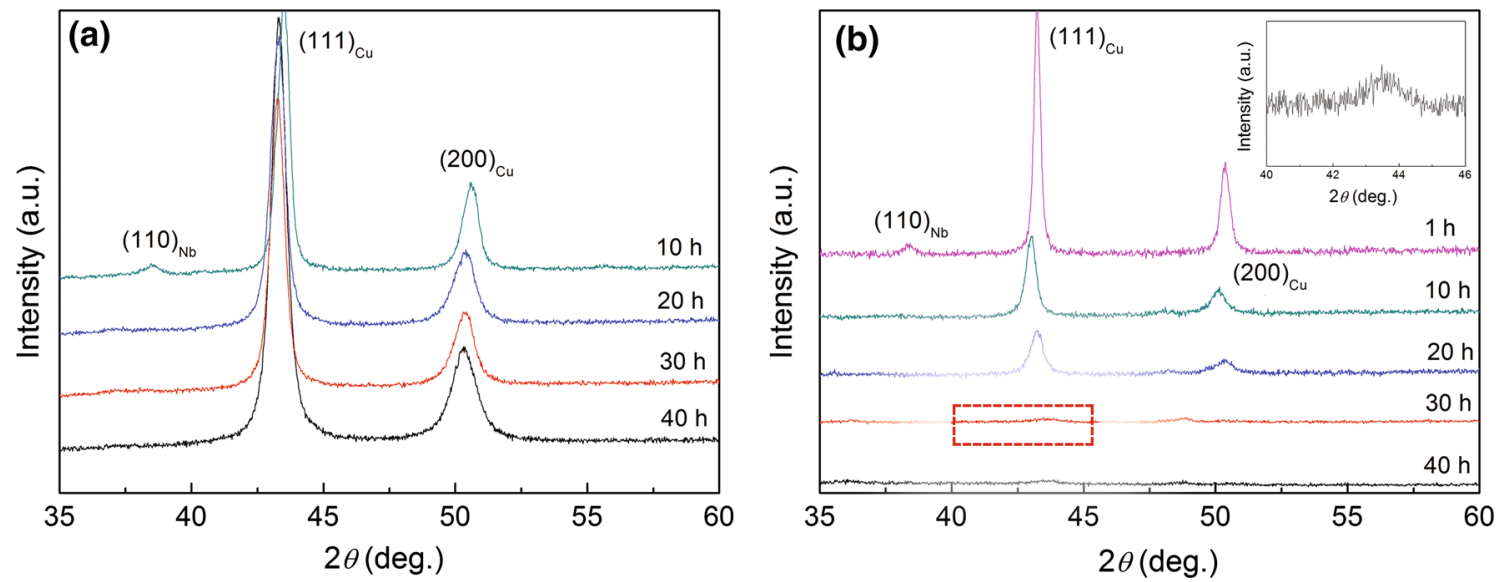

Fig. 1 XRD patterns of $\mathrm{Cu}-7 \mathrm{wt} \% \mathrm{Nb}$ powders at different stages of milling: a Alloy 1; b Alloy 2. Inset is the enlarge image of the region marked by the red box

formation of amorphous phase. Therefore, the type of milling tools has a remarkable effect on the final phase of the asmilled powders.

The variations of crystallite size, internal strain and lattice parameter of the $\mathrm{Cu}$ matrix with the milling time can be determined by analysis of the XRD data. As shown in Fig. 2, the $\mathrm{Cu}$ crystalline grain refinement and internal strain accumulation in Alloy 2 are faster than those in Alloy 1. For Alloy 1, the $\mathrm{Cu}$ crystallite grain size reduces to $\sim 13 \mathrm{~nm}$ after $40 \mathrm{~h}$ milling, confirming the formation of nanocrystalline structure. The $\mathrm{Cu}$ lattice parameter increases from $\sim 0.3618$ to $0.3631 \mathrm{~nm}$, when the milling time increases from 10 to $20 \mathrm{~h}$. It remains almost constant with further milling, indicating the achievement of a steady state. The expansion of the $\mathrm{Cu}$ lattice parameter $\left(a_{\text {pure- }}\right.$ $\mathrm{Cu}=0.3615 \mathrm{~nm}$ ) confirms the fact that the diffusion of $\mathrm{Nb}$ into $\mathrm{Cu}$ takes place during milling, since the atomic radius of $\mathrm{Nb}(0.148 \mathrm{~nm})$ is larger than that of $\mathrm{Cu}(0.128 \mathrm{~nm})$ $[14,17]$. In the case of Alloy 2 , the $\mathrm{Cu}$ crystallite size decreases to $\sim 17 \mathrm{~nm}$ and the lattice strain increases to $\sim 0.53 \%$ after only $20 \mathrm{~h}$ of milling. Furthermore, the $\mathrm{Cu}$ lattice parameter increases to the maximum of $0.3632 \mathrm{~nm}$ after only $10 \mathrm{~h}$ milling, indicating that the dissolution of $\mathrm{Nb}$ into $\mathrm{Cu}$ may be almost completed after $10 \mathrm{~h}$ milling due to the high collision energy.

The SEM image of the powders of Alloy 1 after $40 \mathrm{~h}$ milling shows that almost no $\mathrm{Nb}$ particles remain and a very homogeneous microstructure has been formed (Fig. 3a). The result is consistent with the XRD study. The microstructure of the 40-h milled powders of Alloy 2 is depicted in Fig. 3b. As shown, some particles (light gray) with sizes ranging from 100 to $500 \mathrm{~nm}$ are distributed within the $\mathrm{Cu}$ matrix. The corresponding EDS performed on the dark region (marked as A in Fig. 3b) shows the content of $\mathrm{Nb}$ is about $8.7 \mathrm{wt} \%$ (Fig. 3c), revealing the dissolution of $\mathrm{Nb}$ into $\mathrm{Cu}$. Otherwise, the EDS spectrum of the large bright particle (indicated as $\mathrm{B}$ in Fig. 3b) illustrates that the content of particle is WC (Fig. 3d). Since the frequent collisions between WC balls and containers take place during milling, the wear and tear of the brittle WC
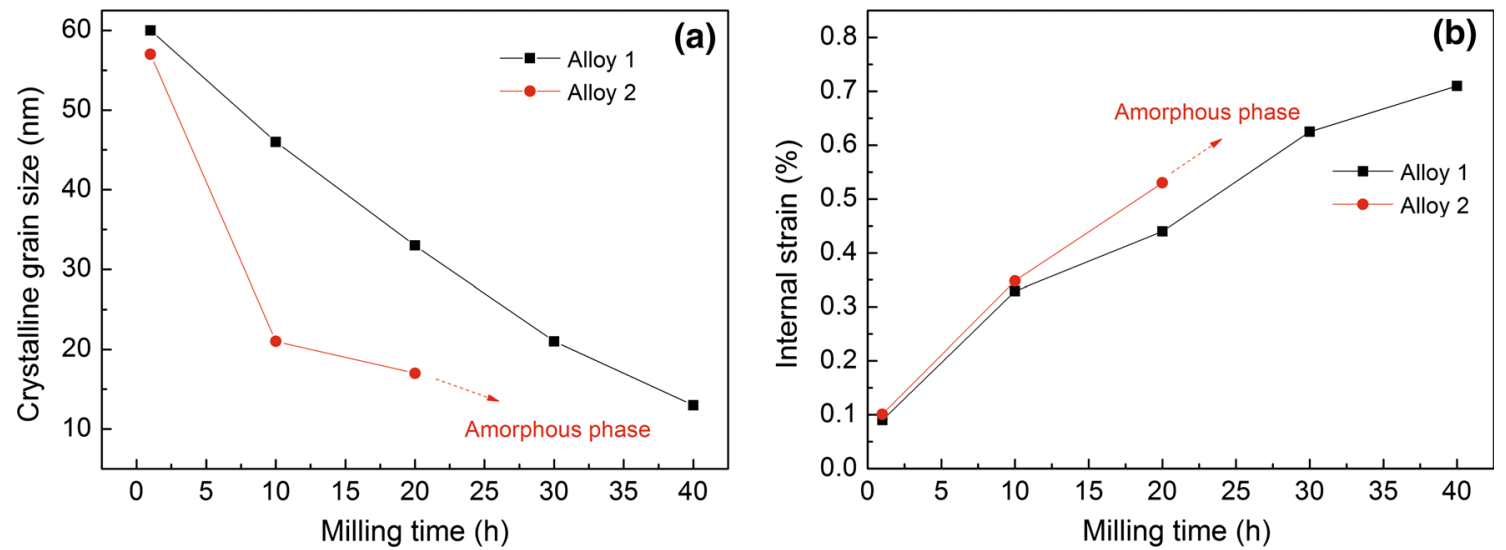

Fig. 2 Variations of crystallite size $\mathbf{a}$ and internal strain $\mathbf{b}$ of the $\mathrm{Cu}$ matrix with different milling time for the powders of Alloy 1; Alloy 2, respectively 

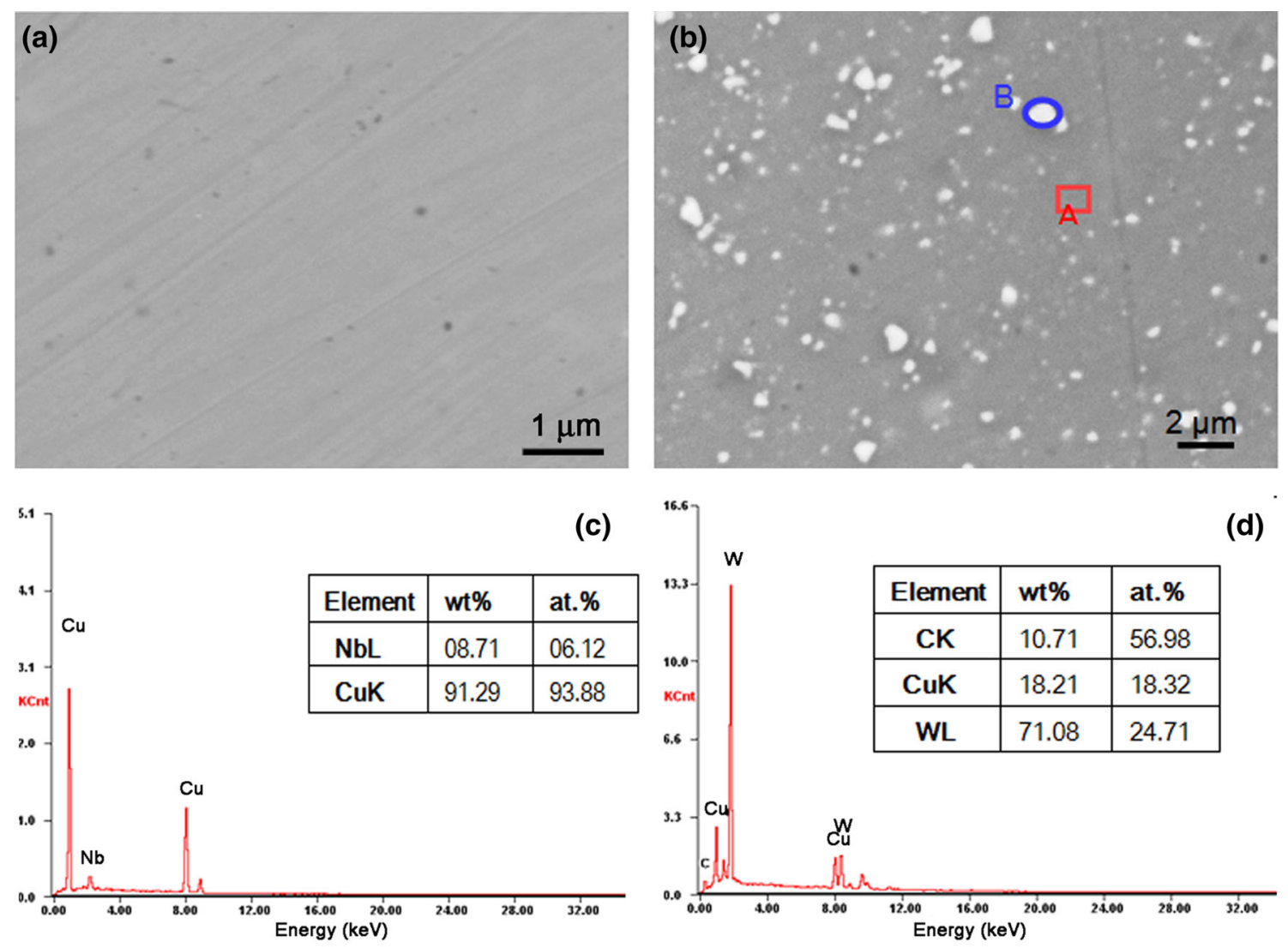

Fig. 3 SEM images of the 40-h milled powders of Alloy 1 a; Alloy 2 b. The corresponding EDS of the region A c, region B d marked in Fig. 3b

grinding medium result in the incorporation of $\mathrm{WC}$ into the powders. Therefore, the disadvantage of WC balls and containers is the contamination of the powders due to the brittleness of WC. It should be pointed out that the absence of WC diffraction peaks in Fig. 1b may be ascribed to the limited resolution of XRD technique used here to detect the small amount of WC particles. The limitation of XRD technique to indentify small amount of particles has been stated in Refs. [9, 10]. Also, it can be assumed that the low WC peaks may be overlapped by the dump peaks from the amorphous phase.

\subsection{Microstructural Characterization and Mechanical Property of Sintered Products}

Figure 4 represents the XRD results of Alloy 1 and Alloy 2 compacted at $900{ }^{\circ} \mathrm{C}$ for $2 \mathrm{~h}$. It is obvious that the diffraction peaks from the sintered products are sharp and strong, indicating the occurrence of grain growth and internal strain reduction during the sintering treatment. From the XRD pattern of Alloy $1, \mathrm{Nb}$ reflections can be detected after hot pressing (Fig. 4a), suggesting that the dissolved $\mathrm{Nb}$ atoms precipitate from the solid solution again. No oxide phase has been detected in the sintered sample. However, a very weak peak from $\mathrm{Fe}_{7} \mathrm{Nb}_{6}$ phase appears after hot pressing. The impurity of $\mathrm{Fe}$ is owing to the abrasions of the milling tools during milling.

In contrast, no $\mathrm{Nb}$ peaks can be detected for sintered Alloy 2, while the signals from $\mathrm{NbC}, \mathrm{W}$ and $\mathrm{WC}$ phases are observed (Fig. 4b). The impurity phase of WC results from the WC balls and containers as illustrated above. The existence of pure metallic tungsten illustrates that the sintering treatment at high temperature may induce the partial decarburization of $\mathrm{WC}$, resulting in the formation of $\mathrm{W}$ and C. The decomposition of WC has also been found in the densification of WC-Fe composites via sintering at $1230{ }^{\circ} \mathrm{C}$ [20]. The in situ formation of $\mathrm{NbC}$ phase reveals that $\mathrm{Nb}$ reacts with $\mathrm{C}$ at the sintering temperature of $900{ }^{\circ} \mathrm{C}$. Since the equilibrium thermodynamic data of Gibbs free energy for $\mathrm{NbC}$ formation are as small as $-137 \mathrm{~kJ} / \mathrm{mol}$, it is easy to drive the in situ reaction between $\mathrm{Nb}$ and $\mathrm{C}$ by the thermal activation [14]. Furthermore, the mechanical energy introduced by MA also accelerates the reaction between $\mathrm{C}$ and $\mathrm{Nb}$ to form $\mathrm{NbC}$ during hot pressing [21].

The $\mathrm{Cu}$ crystallite size and lattice parameter in the compacted samples were determined by XRD. The corresponding average $\mathrm{Cu}$ grain size is found to be $\sim 67$ 

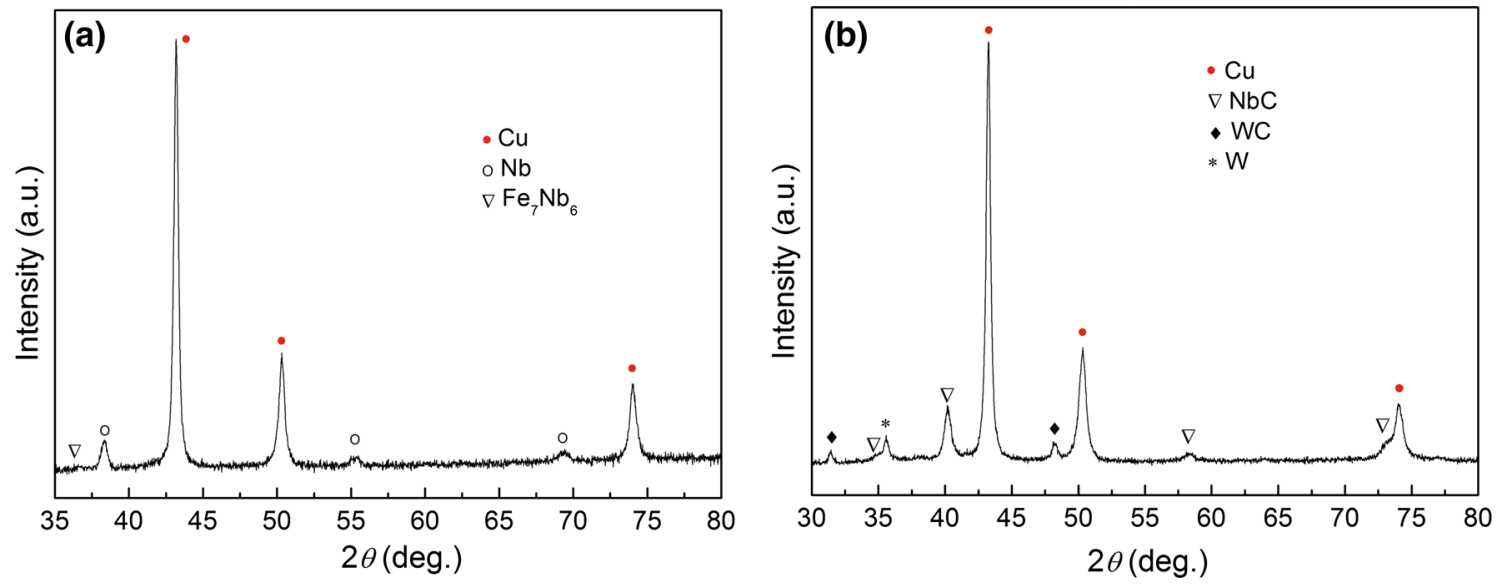

Fig. 4 XRD patterns of Alloy $1 \mathbf{a}$ and Alloy $2 \mathbf{b}$ consolidated at $900{ }^{\circ} \mathrm{C}$ for $2 \mathrm{~h}$

and $\sim 85 \mathrm{~nm}$ for Alloy 1 and Alloy 2 at $900{ }^{\circ} \mathrm{C}$, respectively. Simultaneously, the $\mathrm{Cu}$ lattice parameters for both alloys decrease to the value of pure copper, due to the precipitation of $\mathrm{Nb}$ from $\mathrm{Cu}$ during hot pressing.

The SEM image of sintered Alloy 1 is shown in Fig. 5a. Few pores can be observed, and the $\mathrm{Nb}$ precipitates are dispersed in the $\mathrm{Cu}$ matrix. The average size of $\mathrm{Nb}$ particles amounts to $\sim 185 \mathrm{~nm}$. The SEM image of sintered Alloy 2 shows that the dispersed WC particles are coarse in the size range of 100-650 nm (Fig. 5b). Besides, a few gaps and pores near to WC particles can be detected, which may be attributed to the poor adhesion between $\mathrm{Cu}$ matrix and WC particulate interface.

Figure 6a shows a typical TEM bright-field image of sintered Alloy 1. It can be seen that the structure of the $\mathrm{Cu}$ matrix is fine-nanocrystallined with the average crystallite size of about $81 \mathrm{~nm}$ (Fig. 6b). Figure 6c shows the precipitation of $\mathrm{Nb}$ particles with the size below $10 \mathrm{~nm}$, which was not resolved by SEM technique. Benghalem and Morris have proposed that the growth of the coarse $\mathrm{Nb}$ particles and fine $\mathrm{Nb}$ nanoparticles is controlled by the grain boundary diffusion and volume diffusion, respectively, which give rise to the bimodal distribution of $\mathrm{Nb}$ particle size [8]. The electron diffraction patterns (EDP) of Alloy 1 exhibit both the Debye-Scherrer rings of $\mathrm{Cu}$ and $\mathrm{Nb}$ phases, which further confirms the precipitation of $\mathrm{Nb}$ and the nanocrystalline structure of $\mathrm{Cu}$ (Fig. 6d). Thus, the microstructure of sintered Alloy 1 is a bi-nanostructure, consisting of $\mathrm{Nb}$ nanoparticles distributed within the nanocrystalline $\mathrm{Cu}$ matrix.

TEM micrographs of sintered product of Alloy 2 are shown in Fig. 6e-h. A wide size distribution of $\mathrm{Cu}$ grains ranging from 50 to $200 \mathrm{~nm}$ can be observed (Fig. 6e). Figure $6 \mathrm{f}$ reveals that the average $\mathrm{Cu}$ grain size is $\sim 119 \mathrm{~nm}$, which is relatively larger than that of Alloy 1 . In Fig. $6 \mathrm{~g}$, the fine $\mathrm{NbC}$ nanoparticles in size of 4-10 nm are uniformly distributed within the $\mathrm{Cu}$ matrix. In the EDP of Fig. 6h, presence of (111) plane of $\mathrm{NbC}$ ( $d$ spacing: $0.2576 \mathrm{~nm})$ and $(001)$ plane of WC ( $d$ spacing: $0.2831 \mathrm{~nm})$ was confirmed after careful analysis. Otherwise, the uncontinuous $\mathrm{Cu}$ diffraction rings also illustrate the coarsening of $\mathrm{Cu}$ grains.
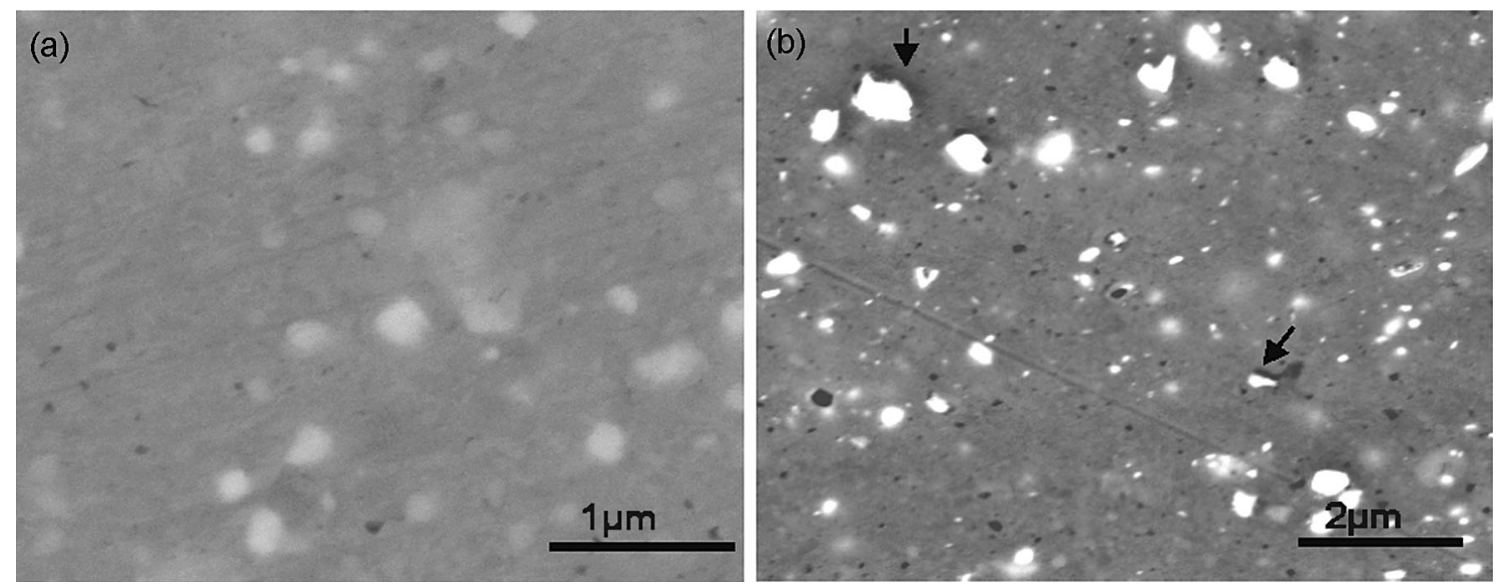

Fig. 5 SEM images of the sintered products of: Alloy $1 \mathbf{a}$; Alloy $2 \mathbf{b}$ 

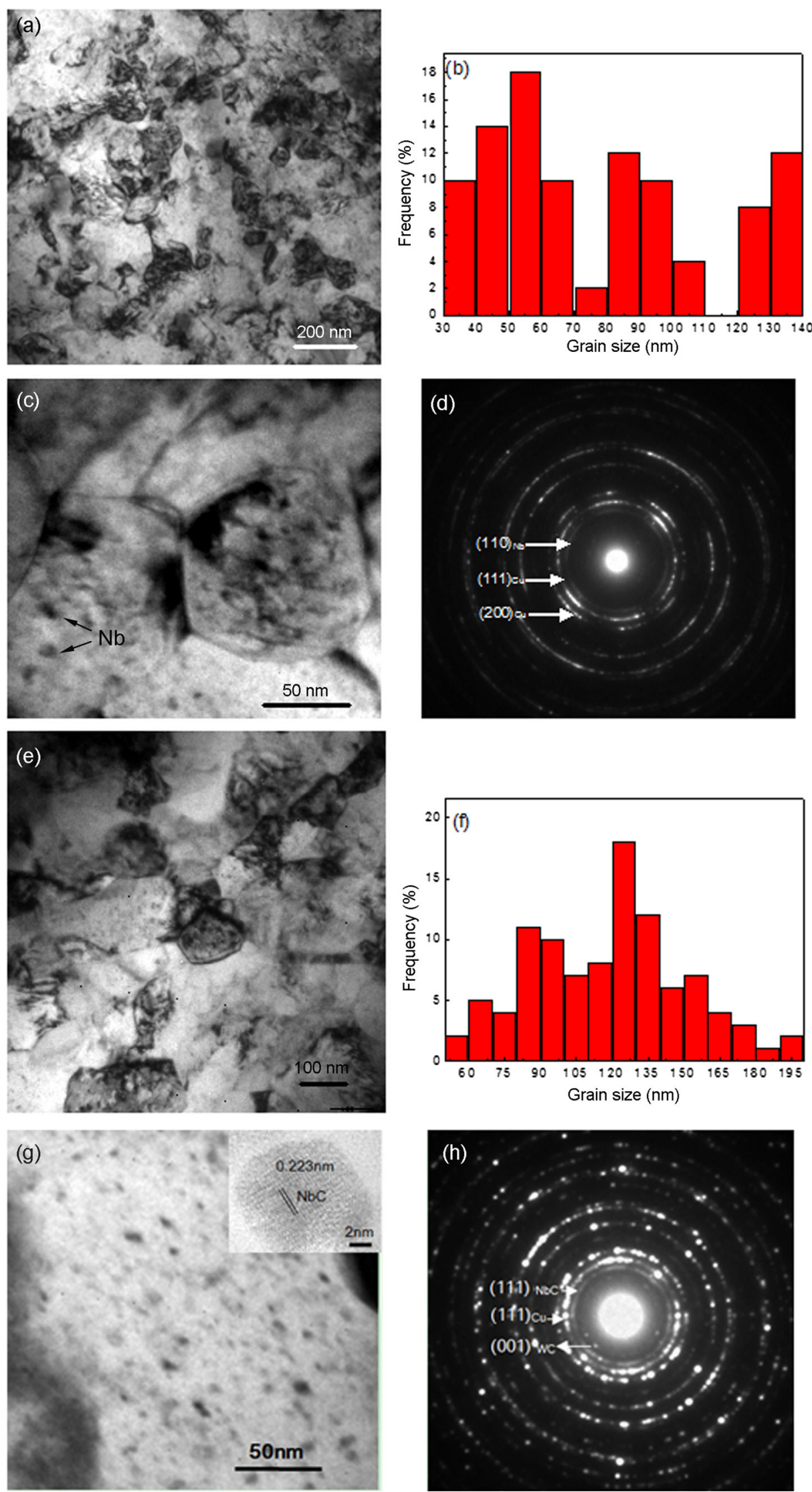
4Fig. 6 TEM images of Alloy 1 and Alloy 2 after hot pressing at $900{ }^{\circ} \mathrm{C}$ for $2 \mathrm{~h}$ : a $\mathrm{Cu}$ nanograins of Alloy $1 ; \mathbf{b} \mathrm{Cu}$ grain size distribution histogram of Alloy 1; c $\mathrm{Nb}$ nanoparticles of Alloy 1; d EDP of Alloy 1; e Cu grains of Alloy 2; $\mathbf{f} \mathrm{Cu}$ grain size distribution histogram of Alloy 2; $\mathbf{g} \mathrm{NbC}$ nanoparticles of Alloy 2, inset showing an HRTEM image of a NbC nanoparticle; $\mathbf{h}$ EDP of Alloy 2

Microhardness testing was performed on the sintered specimens to analyze the mechanical property. The results show that the microhardness values of the sintered products of Alloy 1 and Alloy 2 are 302 and $322 \mathrm{HV}$, respectively, which are much higher than that of pure copper. It is well known that the mechanical properties of metallic materials are affected by lattice defects, such as solute atoms, grain boundaries, dislocations and second phases. In the present case, solid solution strengthening and work hardening for the sintered products can be neglected owing to the precipitation of $\mathrm{Nb}$ from $\mathrm{Cu}$ and the small internal strain. According to the microstructural characterization presented above (Figs. 4, 5, 6), the microstructure of Alloy 1 is built from $\mathrm{Nb}$ nanoparticles that are dispersed in a nanocrystalline $\mathrm{Cu}$ matrix, while the microstructure of Alloy 2 mainly consists of $\mathrm{NbC}$ nanoparticles and coarse WC particles embedded in the submicrometer-sized (or finer) $\mathrm{Cu}$ grains. Hence, the improvement in microhardness of the samples is mainly related to grain boundary hardening and dispersion hardening mechanisms.

On the other hand, considering the dispersion hardening mechanism, the slightly higher microhardness of Alloy 2 than Alloy 1 may be explained by its larger amount of dispersed particles. According to Orowan's mechanism, the strengthening of metal matrix by rigid particles is achieved as follows [22]: $\tau=\mu \boldsymbol{b} / L$, where $\tau$ is the external stress, $\mu$ is the modulus of rigidity of the matrix metal, $\boldsymbol{b}$ is the magnitude of Burgers vector, and $L$ is the interparticle distance. As shown in Fig. 5, a higher density of particle distribution can be observed in Alloy 2 than in Alloy 1 owing to the additive doping of WC phase. Thus, the higher volume percentage of dispersed particles in Alloy 2 results in a decrease in the spacing between the particles. This in turn increases the stress required for forcing the dislocations between the particles. As a result, the strengthening effect caused by the dispersed particles is more significant in Alloy 2 than in Alloy 1, contributing to its higher microhardness.

\section{Conclusions}

1. A single-phase $\mathrm{Cu}-7 \mathrm{wt} \% \mathrm{Nb}$ nanocrystalline solid solution with an average $\mathrm{Cu}$ grain size of $\sim 13 \mathrm{~nm}$ was obtained by MA, when the stainless steel vials and balls were used. Contrary, MA of $\mathrm{Cu}-7 \mathrm{wt} \% \mathrm{Nb}$ powders with $\mathrm{WC}$ vials and balls led to the formation of an amorphous phase. SEM study showed that Alloy 1 possessed a homogeneous microstructure after milling. However, a number of coarse WC particles arose from the milling tools were distributed in the $\mathrm{Cu}$ matrix for Alloy 2.

2. During sintering at $900{ }^{\circ} \mathrm{C}$ for $2 \mathrm{~h}, \mathrm{Nb}$ precipitated from the $\mathrm{Cu}-\mathrm{Nb}$ solid solution and the $\mathrm{Cu}$ matrix kept a nanocrystalline microstructure stably in Alloy 1. Instead, the hot-pressing process resulted in the in situ formation of $\mathrm{NbC}$ nanoparticles instead of $\mathrm{Nb}$ precipitates in Alloy 2. Furthermore, Alloy 2 showed a microstructure with the $\mathrm{Cu}$ grain size ranging from about 50 to $200 \mathrm{~nm}$.

3. The compacted products of Alloy 1 and Alloy 2 showed a high microhardness of 302 and $322 \mathrm{HV}$, respectively. The analysis of strengthening mechanism revealed that the high microhardness of the products was related with the grain boundary hardening and dispersion hardening.

Acknowledgements This work is financially supported by the National Natural Science Foundation of China (No. 51401197).

\section{References}

[1] C. Suryanarayana, Prog. Mater. Sci. 46, 1 (2001)

[2] S. Garroni, S. Enzoa, F. Delogu, Scr. Mater. 83, 49 (2014)

[3] M. Hajizamani, M. Alizadeh, S.A. Jenabali-Jahromi, Acta Metall. Sin. (Engl. Lett.) 29, 39 (2016)

[4] A. Bachmaier, M. Pfaff, M. Stolpe, H. Aboulfad, C. Motz, Acta Mater. 96, 269 (2015)

[5] C. Yang, H.F. Huang, M. Reyes, L. Yan, X.T. Zhou, T. Xia, D.L. Zhang, Acta Metall. Sin. (Engl. Lett.) 28, 809 (2015)

[6] M.R. Akbarpour, H.S. Kim, Mater. Des. 83, 644 (2015)

[7] E. Botcharova, J. Freudenberger, L. Schultz, Acta Mater. 54, 3333 (2006)

[8] A. Benghalem, D.G. Morris, Mater. Sci. Eng. A 161, 255 (1993)

[9] M.D. Abad, S. Parker, D. Kiener, M.M. Primorac, P. Hosemann, J. Alloys Compd. 630, 117 (2015)

[10] S. Mula, H. Bahmanpour, S. Mal, P.C. Kang, M. Atwater, W. Jian, Mater. Sci. Eng. A 539, 330 (2012)

[11] E. Botcharova, M. Heilmaier, J. Freudenbergera, G. Drew, D. Kudashow, U. Martin, L. Schultz, J. Alloys Compd. 351, 119 (2003)

[12] R.S. Lei, M.P. Wang, Z. Li, H.G. Wei, Mater. Sci. Eng. A 528, 4475 (2011)

[13] R.S. Lei, M.P. Wang, H.P. Wang, S.Q. Xu, Mater. Charact. 118, 324 (2016)

[14] B.D. Long, H. Zuhailawati, M. Umemoto, Y. Todaka, R. Othman, J. Alloys Compd. 503, 228 (2010)

[15] H. Zuhailawati, Y. Mahani, J. Alloys Compd. 476, 142 (2009)

[16] B.D. Long, M. Umemoto, Y. Todaka, R. Othman, H. Zuhailawati, Mater. Sci. Eng. A 528, 1750 (2011)

[17] J.H. Li, Y. Dai, X.D. Dai, Comput. Mater. Sci. 43, 1207 (2008)

[18] D. Raabe, S. Ohsaki, K. Hono, Acta Mater. 57, 5254 (2009) 
[19] T.A. Sviridova, E.V. Shelekhov, V.I. Bazilyan, T.R. Chueva, N.V. Shvyndina, N.P. Dyakonova, J. Alloys Compd. 586, S73 (2014)

[20] T.L. Wang, J.H. Li, K.P. Tai, B.X. Liu, Scr. Mater. 57, 157 (2007)
[21] E.A. Álvarez, C.J.R.G. Oliver, J.L. García, Proc. Mater. Sci. 9, 13 (2015)

[22] H. Zuhailawati, T.L. Yong, Mater. Sci. Eng. A 505, 27 (2009) 